\title{
A Pythagorean fuzzy approach to the transportation problem
}

\author{
R. $\operatorname{Kumar}^{1} \cdot$ S. A. Edalatpanah ${ }^{2}$ (D) S. Jha ${ }^{1} \cdot$ R. Singh ${ }^{1}$ \\ Received: 3 January 2019 / Accepted: 15 April 2019 / Published online: 6 May 2019 \\ (c) The Author(s) 2019
}

\begin{abstract}
This paper introduces a simplified presentation of a new computing procedure for solving the fuzzy Pythagorean transportation problem. To design the algorithm, we have described the Pythagorean fuzzy arithmetic and numerical conditions in three different models in Pythagorean fuzzy environment. To achieve our aim, we have first extended the initial basic feasible solution. Then an existing optimality method is used to obtain the cost of transportation. To justify the proposed method, few numerical experiments are given to show the effectiveness of the new model. Finally, some conclusion and future work are discussed.
\end{abstract}

Keywords Pythagorean fuzzy numbers · Transportation problem $\cdot$ Fuzzy numbers $\cdot$ Score function

\section{Introduction}

Zadeh [1] introduced the uncertainty theory which is very useful to cope with imprecise data in many real-life problems. There are certain situations in real life where we tend to find the maximum or minimum, optimum solutions for existing problems. However, in most of the cases, the data to be handled are uncertain, imprecise and inconsistence, the obtained results are not consistent, and, therefore, uncertainty theory came into existence. During the last few decades, the topic of fuzzy optimization has achieved substantial popularity among researchers because of its widespread applications in different branches of network flow problem [2], production [3], shortest path problem [4-8], pick up delivery problem [9], travel salesman problem [10], traffic assignment problem [11].

Transportation problems play a significant role in many real-life applications. This problem aims to maintain the supply from source to destination. Traditionally, it has been generally assumed that transversal costs of supply/demand are expressed in terms of crisp numbers. However, these values are generally imprecise or vague. Consequently, various attempts have been made by researchers for different

S. A. Edalatpanah

saedalatpanah@gmail.com; saedalat@yahoo.com

1 Department of Mathematics, National Institute of Technology, Jamshedpur, Jharkhand, India

2 Department of Industrial Engineering, Ayandegan Institute of Higher Education, Tonekabon, Iran types of transportation problems in the fuzzy environment. In 1984, Chanas et al. [12] suggested fuzzy transportation problems. Since then many authors test the transportation problems in various fuzzy environments such as integer fuzzy [13], multi-objective [14, 15], type-2 fuzzy [16-19], interval-valued fuzzy fractional [20], interval integer fuzzy [21], interval-valued intuitionistic fuzzy [22]. Moreover, we noticed that there are numerous methods to solve this transportation problem such as extension principle [23], ranking function [24], modified Vogel's approximation method [25], Simplex type algorithm [26], fuzzy linear programming [27], fuzzy Russell's method [28], modified best candidate method [29], zero point and zero suffix methods [30] and so on. However, the fuzzy set takes only a membership function. Here, the degree of the non-membership function is just a compliment of the degree of the membership function. There may be a situation where the sum of the membership function and non-membership function is greater than one. Thus, Yager [31, 32] recently introduced another class of non-standard fuzzy subset, i.e., Pythagorean fuzzy set (PFS), where the square sum of the membership and the nonmembership degrees sum is equal to or less than one. There are various methods in the field of PFS to solve multi-criteria decision-making problems such as: extension of TOPSIS [33], Similarity measure [34], Weighted geometric operator [35], alternative queuing method [36], analytic hierarchy process (AHP) [37], Hamacher operation [38], Einstein operations [39, 40], Maclaurin symmetric mean operator [41, 42], extended TODIM methods [43], Bonferroni mean [44], cor- 
Table 1 Important influences of different researchers: real-life applications of operators for decision making

\begin{tabular}{|c|c|c|}
\hline Author and references & Year & Significance influences \\
\hline Li et al. [54] & 2018 & $\begin{array}{l}\text { To handle supplier selection } \\
\text { situation }\end{array}$ \\
\hline Zhou et al. [55] & 2018 & $\begin{array}{l}\text { Pythagorean normal cloud } \\
\text { model for handling the } \\
\text { economic decisions }\end{array}$ \\
\hline Bolturk [56] & 2018 & $\begin{array}{l}\text { Pythagorean fuzzy CODAS } \\
\text { were introduced to handle } \\
\text { supplier selection process } \\
\text { in a manufacturing firm }\end{array}$ \\
\hline Qin [57] & 2018 & $\begin{array}{l}\text { To handle multiple attribute } \\
\text { SIR group decision model }\end{array}$ \\
\hline Wan et al. [58] & 2018 & $\begin{array}{l}\text { To handle the haze } \\
\text { management problem }\end{array}$ \\
\hline Lin et al. [59] & 2018 & $\begin{array}{l}\text { To analysis of inpatient } \\
\text { stroke rehabilitation }\end{array}$ \\
\hline Chen [60] & 2018 & $\begin{array}{l}\text { To handle the financial } \\
\text { decision }\end{array}$ \\
\hline Ilbahar et al. [61] & 2018 & $\begin{array}{l}\text { To handle risk assessment } \\
\text { for occupational health } \\
\text { and safety }\end{array}$ \\
\hline Karasan et al. [62] & 2018 & $\begin{array}{l}\text { To handle landfill site } \\
\text { selection problem }\end{array}$ \\
\hline Zeng et al. [63] & 2018 & $\begin{array}{l}\text { To evaluate classroom } \\
\text { teaching quality }\end{array}$ \\
\hline Ejegwa [64] & 2019 & $\begin{array}{l}\text { Application in medical } \\
\text { diagnosis }\end{array}$ \\
\hline
\end{tabular}

relation coefficients [45], confidence level [46], improved score function [47, 48], and so on; see also [49-53].We have tabulated all those important influences of different researchers who have introduced these real-life applications under the Pythagorean fuzzy environment in Table 1.

Table 2 charts some significant influences towards transportation problem (TP). Based on the previous discussions on TP and currently available data, there are no existing methods which are available for TP under Pythagorean fuzzy environment. Therefore, there is a need to establish a new algorithm for Pythagorean fuzzy transportation problem.

To the nice of our facts, there are no optimization models in literature for TP under Pythagorean fuzzy environment. This complete scenario has motivated us to come up with a new method for solving TP with the Pythagorean fuzzy range which are formulated and solved with the use of the proposed algorithm for the first time.

Pythagorean set theory is documented technique to manage uncertainty in the optimization problem. The most contributions of this paper are as follows.

- This approach helps to resolve a new set of problem with the Pythagorean fuzzy number.
Table 2 Significance influences of the different authors towards TP under various environment

\begin{tabular}{lcl}
\hline Author and references & Year & Significance influences \\
\hline $\begin{array}{l}\text { Korukoğlu and Ballı [65] } \\
\text { Kumar [66] }\end{array}$ & 2011 & $\begin{array}{l}\text { Crisp environment } \\
\text { Fuzzy environment PSK } \\
\text { method }\end{array}$ \\
Chhibber et al. [67] & 2018 & $\begin{array}{c}\text { Type 1 and type 2 fuzzy } \\
\text { environment } \\
\text { Interval type 2 fuzzy } \\
\text { environment } \\
\text { Celik and Akyuz [68] }\end{array}$ 2018 \\
Bharati [69] & 2019 & $\begin{array}{c}\text { fuzzy environment } \\
\text { Interval-valued intuitionistic } \\
\text { fuzzy environment }\end{array}$ \\
Bharati and Singh [22] & 2018 & $\begin{array}{c}\text { Neutrosophic fuzzy } \\
\text { environment }\end{array}$ \\
Ahmad and Adhami [70] & 2018 \\
\hline
\end{tabular}

- We define the TP problem below normal Pythagorean fuzzy surroundings and recommend an efficient solution to locate the corresponding crisp valued.

- Within the literature of Pythagorean fuzzy set, we tend to introduce a scoring approach in conjunction with the proposed method.

This paper is organized as follows: in the next section, some basic knowledge, concepts on Pythagorean fuzzy set theory and arithmetic operation on Pythagorean Fuzzy Numbers (PFNs) are presented. The following section includes the existing method under crisp and fuzzy transportation problems. In the next following section, the proposed method for solving the transportation problem is discussed. In section before conclusion, a few numerical examples are given to reveal the effectiveness of the proposed model. Finally, some conclusions are provided in the last section.

\section{Preliminaries}

Definition 2.1 [31, 71] Let $X$ is a fixed set, a Pythagorean fuzzy set (PFS) is an object having the form

$P=\left\{\left\langle x,\left(\theta_{P}(x), \delta_{P}(x)\right)\right\rangle \mid x \in X\right\}$,

where the function $\theta_{P}(x): X \rightarrow[0,1]$ and $\delta_{P}(x): X \rightarrow$ $[0,1]$ are the degree of membership and non-membership of the element $x \in X$ to $P$, respectively. Also for every $x \in X$, it holds that

$\left(\theta_{P}(x)\right)^{2}+\left(\delta_{P}(x)\right)^{2} \leq 1$ 
Definition 2.2 [31, 71] Let $\tilde{a}_{1}^{P}=\left(\theta_{i}^{P}, \delta_{s}^{P}\right)$ and $\tilde{b}_{1}^{P}=$ $\left(\theta_{o}^{P}, \delta_{f}^{P}\right)$ be two Pythagorean Fuzzy Numbers (PFNs).Then the arithmetic operations are as follows:

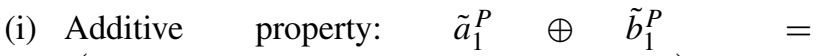
$\left(\sqrt{\left(\theta_{i}^{P}\right)^{2}+\left(\theta_{o}^{P}\right)^{2}-\left(\theta_{i}^{P}\right)^{2} \cdot\left(\theta_{o}^{P}\right)^{2}}, \delta_{s}^{P} \cdot \delta_{f}^{P}\right)$

(ii) Multiplicative property: $\tilde{a}_{1}^{P} \otimes \tilde{b}_{1}^{P}=$ $\left(\theta_{i}^{P} \cdot \theta_{o}^{P}, \sqrt{\left(\delta_{s}^{P}\right)^{2}+\left(\delta_{f}^{P}\right)^{2}-\left(\delta_{s}^{P}\right)^{2} \cdot\left(\delta_{f}^{P}\right)^{2}}\right)$

(iii) Scalar product: $k \cdot \tilde{a}_{1}^{P}=\left(\sqrt{1-\left(1-\theta_{i}^{P}\right)^{k}},\left(\delta_{s}^{P}\right)^{k}\right)$, where $k$ is nonnegative const..i.e. $k \succ 0$

Definition 2.3 [31, 71] (Comparison of two PFNs) Let $\tilde{a}_{1}^{P}=$ $\left(\theta_{i}^{P}, \delta_{s}^{P}\right)$ and $\tilde{b}_{1}^{P}=\left(\theta_{o}^{P}, \delta_{f}^{P}\right)$ be two PFNs such that the score and accuracy function are as follows:

(i) Score function: $S\left(\tilde{a}_{1}^{P}\right)=\frac{1}{2}\left(1-\left(\theta_{i}^{P}\right)^{2}-\left(\delta_{s}^{P}\right)^{2}\right)$

(ii) Accuracy function: $H\left(\tilde{a}_{1}^{P}\right)=\left(\theta_{i}^{P}\right)^{2}+\left(\delta_{s}^{P}\right)^{2}$

Then the following five cases arise:

Case $1 \quad \tilde{a}_{1}^{P} \succ \tilde{b}_{1}^{P}$ iff $S\left(\tilde{a}_{1}^{P}\right) \succ S\left(\tilde{b}_{1}^{P}\right)$

Case $2 \tilde{a}_{1}^{P} \prec \tilde{b}_{1}^{P}$ iff $S\left(\tilde{a}_{1}^{P}\right) \prec S\left(\tilde{b}_{1}^{P}\right)$

Case 3 if $S\left(\tilde{a}_{1}^{P}\right)=S\left(\tilde{b}_{1}^{P}\right)$ and $H\left(\tilde{a}_{1}^{P}\right) \prec H$ $\left(\tilde{b}_{1}^{P}\right)$ then $\tilde{a}_{1}^{P} \prec \tilde{b}_{1}^{P}$

Case 4 if $S\left(\tilde{a}_{1}^{P}\right)=S\left(\tilde{b}_{1}^{P}\right)$ and $H\left(\tilde{a}_{1}^{P}\right) \succ H$ $\left(\tilde{b}_{1}^{P}\right)$ then $\tilde{a}_{1}^{P} \succ \tilde{b}_{1}^{P}$

Case 5 if $S\left(\tilde{a}_{1}^{P}\right)=S\left(\tilde{b}_{1}^{P}\right)$ and $H\left(\tilde{a}_{1}^{P}\right)=H$ $\left(\tilde{b}_{1}^{P}\right)$ then $\tilde{a}_{1}^{P}=\tilde{b}_{1}^{P}$

\section{Existing model in the crisp transportation environment}

Let us consider " $m$ " sources and " $n$ " destinations. In the transportation problem, the objective is to minimize the cost of distributing a product from these sources to the destinations, but the demand and supply of the product with the following assumptions and constraints are crisp:

$m$ The total number of sources existing in the network

$n \quad$ The total number of destination nodes

$i \quad$ The source index for all $m$

$j \quad$ The destination index for all $n$ $x_{i j}$ The number of unit of product transported from source to destination

$c_{i j}^{P} \quad$ The Pythagorean fuzzy cost of one unit quantity transported from $i$ th source to $j$ th destination

$c_{i j}$ The crisp cost of one unit of quantity

$a_{i j}$ The available supply quantity in the crisp environment from each source

$a_{i j}^{P} \quad$ The available supply quantity in the Pythagorean fuzzy environment from each source

$b_{i j}$ The market demand quantity in the crisp environment from each destination

$b_{i j}^{P} \quad$ The market demand quantity in the Pythagorean fuzzy environment from each destination.

Then, the crisp transportation problem is as follows:

$\operatorname{Min} Z=\sum_{i=0}^{m} \sum_{j=0}^{n} x_{i j} \cdot c_{i j}$

Subject to

$\sum_{j=0}^{n} x_{i j}=a_{i}=$ supply, where $i=1, \ldots, m$

$\sum_{i=0}^{m} x_{i j}=b_{i}=$ demand, where $j=1, \ldots, m$

$x_{i j} \geq 0 \quad \forall i, j$.

Furthermore, if we replaced the parameter $c_{i j}$ from Eq. (3) into Pythagorean fuzzy (PyF) parameters, i.e., $c_{i j}^{P}$, then the new LP model obtained is called as Type I Pythagorean fuzzy transportation (T1PyFT) problem, and it is shown as the following:

$\operatorname{Min} Z=\sum_{i=0}^{m} \sum_{j=0}^{n} x_{i j} \cdot c_{i j}^{P}$.

Subject to

$\sum_{j=0}^{n} x_{i j}=a_{i}=$ supply, where $i=1, \ldots, m$

$\sum_{i=0}^{m} x_{i j}=b_{i}=$ demand, where $j=1, \ldots, m$

$x_{i j} \geq 0 \quad \forall i, j$.

Again, if the decision maker will not be sure about the unit transportation supply and demand units, we replace the parameters $a_{i j}$ and $b_{i j}$ into PyF parameters. Then this type of 
problem is known as Type II Pythagorean fuzzy transportation (T2PyFT) problem and it is shown in the below model:

$\operatorname{Min} Z=\sum_{i=0}^{m} \sum_{j=0}^{n} x_{i j} \cdot c_{i j}$.

\section{Subject to}

$$
\begin{aligned}
& \sum_{j=0}^{n} x_{i j}=a_{i}^{P}, \\
& \sum_{i=0}^{m} x_{i j}=b_{j}^{P}, \\
& x_{i j} \geq 0 \quad \forall i, j .
\end{aligned}
$$

Lastly, if the decision maker will not be sure about the transportation cost, supply and demand unit, we replace the parameter $c_{i j}, a_{i j}$ and $b_{i j}$ into PyF parameters. Then this type of problem is known as Type III Pythagorean fuzzy transportation (T3PyFT) problem and it is shown in the following model:

$\operatorname{Min} Z=\sum_{i=0}^{m} \sum_{j=0}^{n} x_{i j} \cdot c_{i j}^{P}$.
Subject to

$$
\begin{aligned}
& \sum_{j=0}^{n} x_{i j}=a_{i}^{P}, \\
& \sum_{i=0}^{m} x_{i j}=b_{j}^{P}, \\
& x_{i j} \geq 0 \quad \forall i, j .
\end{aligned}
$$

\section{Proposed algorithms for solving three different types of PyF transportation models}

In this section, we propose a new algorithm (Main Algorithm) to solve all types of TP under Pythagorean fuzzy environment. This method contains two sub-algorithms. The first sub-algorithm (Algorithm 1) presents a method to find an initial basic feasible solution for TP and the second subalgorithm (Algorithm 2) is an existing optimality method for calculation of the cost of transportation. These algorithms are as follows:

\section{Main Algorithm}

Start,

Step 1: First, choose any of the models to solve the PyFN transportation problem.

Step 1a: If it is Type-I PyFN transportation problem, then calculate the score value of each PyFN cost and replace all the PyFN costs by its score value to obtain the classical transportation problem.

Step 1b: If it is Type-II PyFN transportation problem, then calculate the score value of each PyFN supply and demand unit and replace all the PyFN supply and demand unit by its score value to obtain the classical transportation problem.

Step 1c: If it is Type-III PyFN transportation problem, then calculate the score value of each PyFN cost, PyFN supply, PyFN demand unit and replace all the PyFN cost, PyFN supply, and PyFN demand unit by its score value to obtain the classical transportation problem.

Step 2: To check the balance of transportation, we execute:

$$
\sum_{j=0}^{n} b_{i}=\sum_{i=0}^{m} a_{i}
$$

i.e., Demand = supply.

If demand is not equal to supply, then add dummy variable on Demand/Supply and make it balance and Proceed with the balanced problem.

Step 3: To find the initial basic feasible solution, use the Algorithm 1.

Step 4: Formulate the transportation problem into crisp transportation problem.

Step 5: Test the optimality of the transportation problem by Algorithm 2 .

Step 6: Substitute all $x_{i j}$ in the objective function to get the transportation cost.

End. 


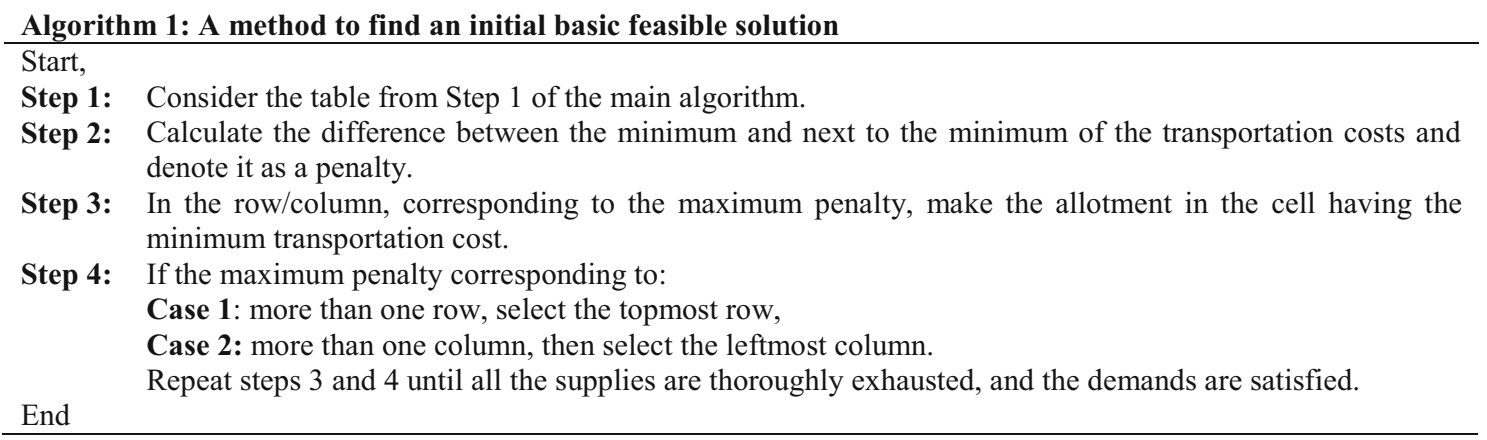

Algorithm 2: A method to test the optimality
Start,
Step 1: Consider the LP model from Step 4 in the main algorithm.
Step 2: Find the optimal solution using any of the optimal software such as lingo or MATLAB and find all the
value of $x_{i j}$
End

\section{Illustrative example}

In this section, some examples are provided to illustrate the potential application of the proposed method.

Example 5.1 (T1PyFN model) Consider a transportation problem with the conditions of Table 3 .

Step 1 Calculate the score value of each PFN cost, replace all them by its score value and obtain a crisp transportation problem. This step is shown in Table 4.

Step 2 To check the balance of transportation we execute:

Table 3 Input data for Pythagorean transportation problem of type-I

\begin{tabular}{llllll}
\hline & D1 & D2 & D3 & D4 & Supply \\
\hline O1 & $(0.4,0.7)$ & $(0.5,0.4)$ & $(0.8,0.3)$ & $(0.6,0.3)$ & 26 \\
O2 & $(0.4,0.2)$ & $(0.7,0.3)$ & $(0.4,0.8)$ & $(0.7,0.3)$ & 24 \\
O3 & $(0.7,0.1)$ & $(0.8,0.1)$ & $(0.6,0.4)$ & $(0.9,0.1)$ & 30 \\
Demand & 17 & 23 & 28 & 12 & \\
\hline
\end{tabular}

Table 4 The defuzzified Pythagorean fuzzy transportation problem of Example 5.1

\begin{tabular}{llllll}
\hline & D1 & D2 & D3 & D4 & Supply \\
\hline O1 & 0.335 & 0.545 & 0.775 & 0.635 & 26 \\
O2 & 0.56 & 0.7 & 0.26 & 0.7 & 24 \\
O3 & 0.74 & 0.815 & 0.6 & 0.9 & 30 \\
Demand & 17 & 23 & 28 & 12 & \\
\hline
\end{tabular}

$\sum a_{i}=26+24+30=80$ and

$\sum b_{i}=17+23+28+12=80$.

Therefore, it is a balanced transportation problem.

Step 3 Now to find an initial basic feasible solution, we proceed with Algorithm 1 as it mentions in the main algorithm. After maximum allotting in the cell $(2,3)$ we get a new table. Table 5 shows the first allotment with penalties (Tables 6, 7, 8).

Table 9 shows the initial basic feasible solution of Example 5.1 .

Hence, the initial basic feasible solution (IBFS) is as follows:

$\left(O_{1}, D_{1}\right)=x_{11}=17,\left(O_{1}, D_{2}\right)=x_{12}=9$,

$\left(O_{2}, D_{3}\right)=x_{23}=24,\left(O_{3}, D_{2}\right)=x_{32}=14$,

$\left(O_{3}, D_{3}\right)=x_{33}=4$, and $\left(O_{3}, D_{4}\right)=x_{34}=12$.

Table 5 First allotment with penalties in Example 5.1

\begin{tabular}{|c|c|c|c|c|c|c|}
\hline & D1 & D2 & D3 & D4 & Supply & Penalties \\
\hline $\mathrm{O} 1$ & 0.335 & 0.545 & 0.775 & 0.635 & 26 & 0.21 \\
\hline $\mathrm{O} 2$ & 0.56 & 0.7 & $0.26 \quad 24$ & 0.7 & 24 & 0.3 \\
\hline $\mathrm{O} 3$ & 0.74 & 0.815 & 0.6 & 0.9 & 30 & 0.14 \\
\hline Demand & 17 & 23 & 4 & 12 & & \\
\hline Penalties & 0.225 & 0.155 & 0.34 & 0.065 & & \\
\hline
\end{tabular}


Table 6 Second allotment with penalties in Example 5.1

\begin{tabular}{|c|c|c|c|c|c|c|c|c|}
\hline & D1 & & D2 & D3 & & D4 & Supply & Penalties \\
\hline O1 & 0.335 & 17 & 0.545 & 0.775 & & 0.635 & 9 & 0.21 \\
\hline $\mathrm{O} 2$ & 0.560 & & 0.700 & 0.26 & 24 & 0.700 & - & - \\
\hline $\mathrm{O} 3$ & 0.740 & & 0.815 & 0.600 & & 0.900 & 30 & 0.14 \\
\hline Demand & 17 & & 23 & 4 & & 12 & & \\
\hline Penalties & 0.405 & & 0.27 & 0.175 & & 0.265 & & \\
\hline
\end{tabular}

Table 7 Third allotment with penalties in Example 5.1

\begin{tabular}{|c|c|c|c|c|c|c|c|c|c|}
\hline & D1 & & D2 & & D3 & & D4 & Supply & Penalties \\
\hline $\mathrm{O} 1$ & 0.335 & 17 & 0.545 & 9 & 0.775 & & 0.635 & 9 & 0.09 \\
\hline $\mathrm{O} 2$ & 0.560 & & 0.700 & & 0.26 & 24 & 0.700 & - & - \\
\hline $\mathrm{O} 3$ & 0.740 & & 0.815 & & 0.600 & & 0.900 & 30 & 0.215 \\
\hline Demand & - & & 14 & & 4 & & 12 & & \\
\hline Penalties & - & & 0.27 & & 0.175 & & 0.265 & & \\
\hline
\end{tabular}

Table 8 Complete allotment in Example 5.1

\begin{tabular}{|c|c|c|c|c|c|c|c|c|c|c|}
\hline & D1 & & D2 & & D3 & & D4 & & Supply & Penalties \\
\hline $\mathrm{O} 1$ & 0.335 & 17 & 0.545 & 9 & 0.775 & & 0.635 & & - & 0.09 \\
\hline $\mathrm{O} 2$ & 0.560 & & 0.700 & & 0.26 & 24 & 0.700 & & - & - \\
\hline $\mathrm{O} 3$ & 0.740 & & 0.815 & 14 & 0.60 & 4 & 0.900 & 12 & 30 & 0.215 \\
\hline Demand & - & & 14 & & 4 & & 12 & & & \\
\hline Penalties & - & & 0.27 & & 0.175 & & 0.265 & & & \\
\hline
\end{tabular}

Also, the minimum cost of IBFS is obtained as follows:

$$
\text { Min }=17 \times 0.335+9 \times 0.545+24 \times 0.26+14
$$$$
\times 0.815+4 \times 0.6+12 \times 0.9=41.45 \text {. }
$$

Steps 4-5 Now, we test the optimality of the transportation problem. Since the $m+n-1=6$, it is a degenerate solution, and we need to proceed to test the optimality. To obtain the optimality, we use Lingo software. Therefore, the optimal solution is as follows:

$\left(O_{1}, D_{1}\right)=x_{11}=17,\left(O_{1}, D_{2}\right)=x_{12}=9$,

$\left(O_{2}, D_{3}\right)=x_{23}=24,\left(O_{3}, D_{2}\right)=x_{32}=14$,

$\left(O_{3}, D_{3}\right)=x_{33}=4$, and $\left(O_{3}, D_{4}\right)=x_{34}=12$.

Step 6 Now put all $x_{i j}$ in the above equation; so we get:

$\operatorname{Min}=17 \times 0.335+9 \times 0.545+24 \times 0.26$

$$
+14 \times 0.815+4 \times 0.6+12 \times 0.9 \text {. }
$$

Minimum cost $=41.45$.

Example 5.2 (T2PyFN model) Consider type-II PyFN problem with the conditions of Table 10 where the costs are crisp, but the demand and supply are PFN. The supplies are denoted as Pythagorean fuzzy numbers, i.e.,

$\tilde{s}_{1}^{P}=\left(\theta^{P}, \delta^{P}\right) \approx(0.7,0.1), \tilde{s}_{2}^{P} \approx(0.8,0.1)$,

$\tilde{s}_{3}^{P} \approx(0.9,0.1)$.

Similarly, the demands are also denoted as Pythagorean fuzzy numbers, respectively. We note that $\theta^{P}, \delta^{P}$ represent the maximum degree of the membership (i.e., the degree of acceptance of quantity) and the non-membership (i.e., the degree of rejection of quantity) respectively. Moreover, they will also satisfy the inconsistence information under these conditions, i.e., $0 \leq \theta^{P} \leq 1,0 \leq \delta^{P} \leq 1,0 \leq\left(\theta^{P}\right)^{2}+$ $\left(\delta^{P}\right)^{2} \leq 1$.
Table 9 The initial basic

\begin{tabular}{|c|c|c|c|c|c|c|c|c|c|}
\hline & D1 & & D2 & & D3 & & D4 & & Supply \\
\hline $\mathrm{O} 1$ & 0.335 & 17 & 0.545 & 9 & 0.775 & & 0.635 & & 26 \\
\hline $\mathrm{O} 2$ & 0.560 & & 0.700 & & 0.260 & 24 & 0.700 & & 24 \\
\hline $\mathrm{O} 3$ & 0.740 & & 0.815 & 14 & 0.600 & 4 & 0.900 & 12 & 30 \\
\hline Demand & 17 & & 23 & & 28 & & 12 & & \\
\hline
\end{tabular}
feasible solution of Example 5.1 
Table 10 Input data for Pythagorean transportation problem of type-II

\begin{tabular}{llllll}
\hline & D1 & D2 & D3 & D4 & Supply \\
\hline O1 & 0.0335 & 0.0545 & 0.0775 & 0.0635 & $(0.7,0.1)$ \\
O2 & 0.056 & 0.07 & 0.026 & 0.07 & $(0.8,0.1)$ \\
O3 & 0.074 & 0.0815 & 0.06 & 0.09 & $(0.9,0.1)$ \\
Demand & $(0.4,0.7)$ & $(0.7,0.3)$ & $(0.8,0.1)$ & $\begin{array}{c}(0.60832, \\
0.4)\end{array}$ \\
\hline
\end{tabular}

Solution After executing the steps 1-3, we get the initial basic feasible solution as follows:

$\left(O_{1}, D_{1}\right)=x_{11}=0.3350,\left(O_{1}, D_{2}\right)=x_{12}=0.405$,

$\left(O_{2}, D_{3}\right)=x_{23}=0.8150,\left(O_{3}, D_{2}\right)=x_{32}=0.295$, and

$\left(O_{3}, D_{4}\right)=x_{34}=0.6050$.

Also, the minimum cost of an initial basic feasible solution is

$$
\begin{aligned}
\text { Min }= & 0.0335 \times 0.3350+0.0545 \times 0.405+0.295 \times 0.0815 \\
& +0.026 \times 0.8150+0.07 \times 0.6050=0.132978 .
\end{aligned}
$$

Again, execute the steps 4-6, we get the optimum solution, i.e.:

$\left(O_{1}, D_{1}\right)=x_{11}=0.3350,\left(O_{1}, D_{2}\right)=x_{12}=0.405$,

$\left(O_{2}, D_{3}\right)=x_{23}=0.8150,\left(O_{3}, D_{2}\right)=x_{32}=0.295$, and

$\left(\mathrm{O}_{3}, \mathrm{D}_{4}\right)=x_{34}=0.6050$.

$$
\begin{aligned}
\text { Min }= & 0.0335 \times 0.3350+0.0545 \times 0.405+0.295 \\
& \times 0.0815+0.026 \times 0.8150+0.07 \times 0.6050
\end{aligned}
$$

Minimum cost $=0.132978$.

Example 5.3 Consider type-III PyFN problem with the conditions of Table 11. Here, the supplies are denoted as Pythagorean fuzzy. Similarly, the demands are also denoted as Pythagorean fuzzy numbers $\left(\theta^{P}, \delta^{P}\right)$, respectively. We note that $\theta^{P}, \delta^{P}$ represent the maximum degree of the membership (i.e., the degree of acceptance of quantity) and the non-membership (i.e., the degree of rejection of quantity), respectively. The cost values are also in Pythagorean fuzzy numbers where $C^{P} \approx\left(C_{a}^{P}, C_{r}^{P}\right)$ represents the degree of acceptance and rejection of cost.
Solution After executing the steps 1-3, we get the initial basic feasible solution as follows.

After executing the step 1-3, we get the initial basic feasible solution, i.e., $\left(O_{2}, D_{1}\right)=x_{21}=0.335,\left(O_{1}\right.$, $\left.D_{2}\right)=x_{12}=0.135,\left(O_{2}, D_{2}\right)=x_{22}=0.48,\left(O_{2}\right.$, $\left.D_{3}\right)=x_{23}=0.085,\left(O_{3}, D_{3}\right)=x_{33}=0.815$, and $\left(O_{1}, D_{4}\right)=x_{14}=0.6050$; so the minimum IBFS cost is 0.322775 .

Again, by steps 4-6, we get the optimum solution i.e., $\left(\mathrm{O}_{2}\right.$, $\left.D_{1}\right)=x_{21}=0.335,\left(O_{1}, D_{2}\right)=x_{12}=0.22,\left(O_{2}, D_{2}\right)=$ $x_{22}=0.48,\left(O_{3}, D_{4}\right)=x_{34}=0.085,\left(O_{3}, D_{3}\right)=x_{33}=$ 0.815 , and $\left(O_{1}, D_{4}\right)=x_{14}=0.52$, that the minimum cost is 0.31895 .

\section{Results and discussion}

In Example 5.1, it is clear that the PyFN transportation cost of IBFS is 41.45 which is same as the optimum transportation cost of PyFN transportation problem. Hence, this shows that the optimal value is not more than the IBFS and in Example 5.2, the PyFN transportation cost of IBFS is 0.132978 which is the same as the optimum transportation cost of PyFN transportation problem. Again we observe that the optimum value is not more than the IBFS. However, in Example 5.3 the optimum transportation cost of PyFN transportation problem is 0.31895 , which is less than the transportation cost of IBFS i.e. 0.322775. Therefore, we can say that the proposed method produces lower optimum values when compared with IBFS. The logical comparison for all the above three discussed examples is shown in Table 12. In this table, we can see that the optimal value of PyFN transportation problem is either equal or less than the IBFS solution.

Therefore, we can conclude that our proposed algorithm is a new way to handle the uncertainty in the crisp environment.

\section{Conclusions}

In this paper, the fuzzy Pythagorean transportation problem has been investigated. At that point, we proposed another arrangement approach for understanding whole number esteemed Pythagorean fuzzy transportation problem. Moreover, we study three different models in the Pythagorean fuzzy environment. The existing arithmetic operations on
Table 11 Input data for Pythagorean transportation problem of type-III

\begin{tabular}{llllll}
\hline & D1 & D2 & D3 & D4 & Supply \\
\hline O1 & $(0.1,0.9)$ & $(0.2,0.8)$ & $(0.1,0.8)$ & $(0.1,0.9)$ & $(0.7,0.1)$ \\
O2 & $(0.01,0.99)$ & $(0.3,0.9)$ & $(0.3,0.8)$ & $(0.1,0.7)$ & $(0.8,0.1)$ \\
O3 & $(0.1,0.8)$ & $(0.4,0.8)$ & $(0.4,0.9)$ & $(0.2,0.9)$ & $(0.9,0.1)$ \\
Demand & $(0.4,0.7)$ & $(0.7,0.3)$ & $(0.8,0.1)$ & $(0.60832,0.4)$ & \\
\hline
\end{tabular}


Table 12 Logical comparison of IBFS with optimum value

\begin{tabular}{lll}
\hline Sr. no. & Example & Logical comparison with initial basic feasible solution and optimal solution \\
\hline 1. & Example 5.1 & Initial basic feasible solution $\geq$ after optimality test \\
2. & Example 5.2 & Initial basic feasible solution $\geq$ after optimality test \\
3. & Example 5.3 & Initial basic feasible solution $>$ after optimality test \\
\hline
\end{tabular}

the Pythagorean fuzzy numbers and a score function are employed to find the optimum solutions. The proposed algorithm is a new way to handle the uncertainty in the crisp environment. In the future, the proposed method can be applied to real-world problems in the field of assignment, job scheduling, shortest path problem, and so on.

Open Access This article is distributed under the terms of the Creative Commons Attribution 4.0 International License (http://creativecomm ons.org/licenses/by/4.0/), which permits unrestricted use, distribution, and reproduction in any medium, provided you give appropriate credit to the original author(s) and the source, provide a link to the Creative Commons license, and indicate if changes were made.

\section{References}

1. Zadeh LA (1965) Fuzzy sets. Inf Control 8:338-353

2. Ford LR, Fulkerson DR (1957) A simple algorithm for finding maximal network flows and an application to the hitchcock problem. Can J Math 9:210-218

3. Sakawa M, Nishizaki I, Uemura Y (2001) Fuzzy programming and profit and cost allocation for a production and transportation problem. Eur J Oper Res 131:1-15

4. Kumar R, Edalatpanah SA, Jha S, Broumi S, Dey A (2018) Neutrosophic shortest path problem. Neutrosoph Sets Syst 23:5-15

5. Kumar R, Edalatpanah SA, Jha S, Singh R (2019) A novel approach to solve gaussian valued neutrosophic shortest path problems. Int J Eng Adv Technol 8(3):347-353

6. Kumar R, Edalatpanah SA, Broumi S, Jha S, Singh R, Dey A (2019) A multi objective programming approaches to solve integer valued neutrosophic shortest path problems. Neutrosoph Sets Syst 24:134-149

7. Kumar R, Jha S, Singh R (2018) A different approach for solving the shortest path problem under mixed fuzzy environment. Int $\mathbf{J}$ Fuzzy Syst Appl 9(2):6

8. Kumar R, Jha S, Singh R (2017) Shortest path problem in network with type-2 triangular fuzzy arc length. J Appl Res Ind Eng 4:1-7

9. Ropke S, Pisinger D (2006) An adaptive large neighborhood search heuristic for the pickup and delivery problem with time windows. Transp Sci 40:455-472

10. Flood MM (1956) The traveling-salesman problem. Oper Res 4:61-75

11. Dafermos SC (1972) The traffic assignment problem for multiclassuser transportation networks. Transp Sci 6:73-87

12. Chanas S, Kołodziejczyk W, Machaj A (1984) A fuzzy approach to the transportation problem. Fuzzy Sets Syst 13:211-221

13. Tada M, Ishii H (1996) An integer fuzzy transportation problem. Comput Math Appl 31:71-87

14. Hashmi N, Jalil SA, Javaid S (2019) A model for two-stage fixed charge transportation problem with multiple objectives and fuzzy linguistic preferences. Soft Comput. https://doi.org/10.1007/ s00500-019-03782-1
15. Li L, Lai KK (2000) A fuzzy approach to the multiobjective transportation problem. Comput Oper Res 27:43-57

16. Liu P, Yang L, Wang L, Li S (2014) A solid transportation problem with type-2 fuzzy variables. Appl Soft Comput 24:543-558

17. Kundu P, Kar S, Maiti M (2014) Fixed charge transportation problem with type-2 fuzzy variables. Inf Sci 255:170-186

18. Singh SK, Yadav SP (2016) A new approach for solving intuitionistic fuzzy transportation problem of type-2. Ann Oper Res 243:349-363

19. Gupta G, Kumari A (2017) An efficient method for solving intuitionistic fuzzy transportation problem of type-2. Int J Appl Comput Math 3:3795-3804

20. Arora J (2018) An algorithm for interval-valued fuzzy fractional transportation problem. Skit Res J 8:71-75

21. Akilbasha A, Pandian P, Natarajan G (2018) An innovative exact method for solving fully interval integer transportation problems. Inform Med Unlock 11:95-99

22. Bharati SK, Singh SR (2018) Transportation problem under interval-valued intuitionistic fuzzy environment. Int J Fuzzy Syst 20:1511-1522

23. Liu S-T, Kao C (2004) Solving fuzzy transportation problems based on extension principle. Eur J Oper Res 153:661-674

24. Kaur A, Kumar A (2011) A new method for solving fuzzy transportation problems using ranking function. Appl Math Model 35:5652-5661

25. Samuel AE, Venkatachalapathy M (2011) Modified Vogel's approximation method for fuzzy transportation problems. Appl Math Sci 5:1367-1372

26. Gani AN, Samuel AE, Anuradha D (2011) Simplex type algorithm for solving fuzzy transportation problem. Tamsui Oxford J Inf Math Sci 27:89-98

27. Kour D, Mukherjee S, Basu K (2017) Solving intuitionistic fuzzy transportation problem using linear programming. Int J Syst Assur Eng Manag 8:1090-1101

28. Narayanamoorthy S, Saranya S, Maheswari S (2013) A method for solving fuzzy transportation problem (FTP) using fuzzy Russell's method. Int J Intell Syst Appl 5:71-75

29. Dinagar DS, Keerthivasan R (2018) Solving fuzzy transportation problem using modified best candidate method. J Comput Math Sci 9:1179-1186

30. Ngastiti PTB, Surarso B, Sutimin (2018) Zero point and zero suffix methods with robust ranking for solving fully fuzzy transportation problems. J Phys Conf Ser 1022:01-09

31. Yager RR (2014) Pythagorean membership grades in multicriteria decision making. IEEE Trans Fuzzy Syst 22:958-965

32. Yager RR (2013) Pythagorean fuzzy subsets. In: 2013 joint IFSA world congress and NAFIPS annual meeting (IFSA/NAFIPS), pp $57-61$

33. Zhang X, Xu Z (2014) Extension of TOPSIS to multiple criteria decision making with Pythagorean fuzzy sets. Int J Intell Syst 29:1061-1078

34. Zhang X (2016) A novel approach based on similarity measure for Pythagorean fuzzy multiple criteria group decision making. Int $\mathbf{J}$ Intell Syst 31:593-611

35. Ma Z, Xu Z (2016) Symmetric Pythagorean fuzzy weighted geometric/averaging operators and their application in multicriteria decision-making problems. Int J Intell Syst 31:1198-1219 
36. Gou X, Xu Z, Liao H (2016) Alternative queuing method for multiple criteria decision making with hybrid fuzzy and ranking information. Inf Sci 357:144-160

37. Mohd WRW, Lazim A (2017) Pythagorean fuzzy analytic hierarchy process to multi-criteria decision making. AIP Conf Proc 1905:040020

38. Wu S-J, Wei G-W (2017) Pythagorean fuzzy hamacher aggregation operators and their application to multiple attribute decision making. Int J Knowl Based Intell Eng Syst 21:189-201

39. Garg H (2016) A new generalized Pythagorean fuzzy information aggregation using einstein operations and its application to decision making. Int J Intell Syst 31(9):886-920

40. Garg H (2017) Generalized Pythagorean fuzzy geometric aggregation operators using einstein t-norm and t-conorm for multicriteria decision-making process. Int J Intell Syst 32(6):597-630

41. Wei G, Garg H, Gao H, Wei C (2018) Interval-valued Pythagorean fuzzy maclaurin symmetric mean operators in multiple attribute decision making. IEEE Access 6:7866-7884

42. Wei G, Lu M (2017) Pythagorean fuzzy maclaurin symmetric mean operators in multiple attribute decision making. Int $\mathbf{J}$ Intell Syst 33:1043-1070

43. Geng Y, Liu P, Teng F, Liu Z (2017) Pythagorean fuzzy uncertain linguistic TODIM method and their application to multiple criteria group decision making. J Intell Fuzzy Syst 33:3383-3395

44. Jing N, Xian S, Xiao Y (2017) Pythagorean triangular fuzzy linguistic bonferroni mean operators and their application for multiattribute decision making. In: 2nd IEEE international conference on computational intelligence and applications (ICCIA), pp 435-439

45. Garg H (2016) A novel correlation coefficients between pythagorean fuzzy sets and its applications to decision-making processes. Int J Intell Syst 31:1234-1252

46. Garg H (2017) Confidence levels based Pythagorean fuzzy aggregation operators and its application to decision-making process. Comput Math Org Theory 23:546-571

47. Garg H (2018) A linear programming method based on an improved score function for interval-valued pythagorean fuzzy numbers and its application to decision-making. Int J Uncertainty Fuzziness Knowl Based Syst 26:67-80

48. Garg H (2017) A new improved score function of an interval-valued pythagorean fuzzy set based topsis method. Int J Uncertainty Quant 7:463-474

49. Garg H (2016) A novel accuracy function under interval-valued Pythagorean fuzzy environment for solving multicriteria decision making problem. J Intell Fuzzy Syst 31(1):529-540

50. Chen S, Zeng J, Li X (2016) A hybrid method for pythagorean fuzzy multiple-criteria decision making. Int J Inf Technol Decis Making 15(2):403-422

51. Peng X, Yang Y (2016) Pythagorean fuzzy choquet integral based MABAC method for multiple attribute group decision making. Int J Intell Syst 31(10):989-1020

52. Lu M, Wei G, Alsaadi FE, Hayat T, Alsaedi A (2017) Hesitant Pythagorean fuzzy hamacher aggregation operators and their application to multiple attribute decision making. J Intell Fuzzy Syst 33(2):1105-1117

53. Wei G, Lu M (2017) Dual hesitant pythagorean fuzzy hamacher aggregation operators in multiple attribute decision making. Arch Control Sci 27(3):365-395

54. Li Z, Wei G, Lu M (2018) Pythagorean fuzzy hamy mean operators in multiple attribute group decision making and their application to supplier selection. Symmetry 10:505

55. Zhou J, Su W, Baležentis T, Streimikiene D (2018) Multiple criteria group decision-making considering symmetry with regards to the positive and negative ideal solutions via the Pythagorean normal cloud model for application to economic decisions. Symmetry 10(5):140
56. Bolturk E (2018) Pythagorean fuzzy CODAS and its application to supplier selection in a manufacturing firm. J Enterp Inf Manag 31:550-564

57. Qin J (2018) Generalized Pythagorean fuzzy maclaurin symmetric means and its application to multiple attribute sir group decision model. Int J Fuzzy Syst 20:943-957

58. Wan S-P, Li S-Q, Dong J-Y (2018) A three-phase method for Pythagorean fuzzy multi-attribute group decision making and application to haze management. Comput Ind Eng 123:348-363

59. Lin Y-L, Ho L-H, Yeh S-L, Chen T-Y (2018) A Pythagorean fuzzy topsis method based on novel correlation measures and its application to multiple criteria decision analysis of inpatient stroke rehabilitation. Int J Comput Intell Syst 12(1):410-425

60. Chen T-Y (2018) An outranking approach using a risk attitudinal assignment model involving Pythagorean fuzzy information and its application to financial decision making. Appl Soft Comput 71:460-487

61. Ilbahar E, Karaşan A, Cebi S, Kahraman C (2018) A novel approach to risk assessment for occupational health and safety using Pythagorean fuzzy AHP \& fuzzy inference system. Saf Sci 103:124-136

62. Karasan A, Ilbahar E, Kahraman C (2018) A novel pythagorean fuzzy AHP and its application to landfill site selection problem. Soft Comput. https://doi.org/10.1007/s00500-018-3649-0

63. Zeng S, Wang N, Zhang C, Su W (2018) A novel method based on induced aggregation operator for classroom teaching quality evaluation with probabilistic and pythagorean fuzzy information. Eurasia J Math Sci Technol Educ 14:3205-3212

64. Ejegwa PA (2019) Improved composite relation for pythagorean fuzzy sets and its application to medical diagnosis. Granul Comput. https://doi.org/10.1007/s41066-019-00156-8

65. Korukoğlu S, Ballı S (2011) A improved Vogel's approximation method for the transportation problem. Math Comput Appl 16:370-381

66. Kumar PS (2018) PSK method for solving intuitionistic fuzzy solid transportation problems. IJFSA 7(4):62-99

67. Chhibber D, Bisht DCS, Srivastava PK (2019) Ranking approach based on incenter in triangle of centroids to solve type-1 and type-2 fuzzy transportation problem. AIP Conf Proc 2061:020022

68. Celik E, Akyuz E(2018) An interval type-2 fuzzy AHP and TOPSIS methods for decision-making problems in maritime transportation engineering: the case of ship loader. Ocean Eng 155:371-381

69. Bharati SK (2019) Trapezoidal intuitionistic fuzzy fractional transportation problem in soft computing for problem solving. Singapore 20:833-842

70. Ahmad F, Adhami AY (2018) Neutrosophic programming approach to multiobjective nonlinear transportation problem with fuzzy parameters. Int J Manag Sci Eng Manag. https://doi.org/10. 1080/17509653.2018.1545608

71. Reformat M, Yager RR (2014) Suggesting recommendations using pythagorean fuzzy sets illustrated using netflix movie data. In: Information processing and management of uncertainty in knowledge-based systems - 15 th international conference, IPMU, Montpellier, France, July 15-19, Proceedings, Part I, pp 546-556

Publisher's Note Springer Nature remains neutral with regard to jurisdictional claims in published maps and institutional affiliations. 